\title{
Wolfram-like syndrome
}

INSERM

\section{Source}

INSERM. (1999). Orphanet: an online rare disease and orphan drug data base. Wolframlike syndrome. ORPHA:411590

Wolfram-like syndrome is a rare endocrine disease characterized by the triad of adultonset diabetes mellitus, progressive hearing loss (usually presenting in the first decade of life and principally of low to moderate frequencies), and/or juvenile-onset optic atrophy. Psychiatric (i.e. anxiety, depression, hallucinations) and sleep disorders, the only neurologic abnormalities observed in this disease, have been reported in rare cases. Unlike Wolfram syndrome, patients with Wolfram-like syndrome do not report endocrine or cardiac findings. 